\title{
Henoch scholein purpura presenting as distal ileitis in a postmenopausal woman: A rare case report
}

\author{
Ramya SG ${ }^{1}$, SK Nelliappa Ganesan ${ }^{2}$, SN Meenakshi Sundari ${ }^{3}$, V Sundaravadivelu ${ }^{4}$, P Priyadharshini ${ }^{5}$ \\ ${ }^{1}$ Dr. Ramya SG, Assistant Professor; ${ }^{2}$ Dr. SK Nelliappa Ganesan, Professor; ${ }^{3}$ Dr. SN Meenakshi Sundari, Associate \\ Professor; ${ }^{4}$ Dr. V Sundaravadivelu, Professor \& HOD; ${ }^{5}$ Dr. P Priyadharshini, Intern. All are affiliated to Department of \\ General Medicine, SRM Medical College Hospital \& Research Centre, Kattankulathur, Kanchipuram, Tamilnadu, India.
}

Address for Correspondence: Dr. Ramya SG, Email: dr.sgramya@gmail.com

\begin{abstract}
Henoch Schonlein purpura (HSP) is a small vessel vasculitis leading to deposition of immune IgA complexes. It presents with a tetrad of symptoms, including a purpuric rash occurring on the lower extremities, gastro intestinal involvement, renal involvement and arthritis. HSP is self limited and primarily affects children. The etiology is unknown. Treatment is mainly supportive therapy with analgesics and in severe cases, steroids are used. Here we report a rare case of Henoch Scholein purpura in a postmenopausal woman presenting as acute distal ileitis.
\end{abstract}

Keywords: Distal Ileitis, Henoch Scholein purpura, Small vessel vasculitis.

\section{Introduction}

Henoch Schonlein purpura (HSP) is a leucocytoclastic vasculitis involving small vessels, leading to deposition of immune IgA complexes. It presents with a tetrad of symptoms, including a purpuric rash occurring on the lower extremities, abdominal pain, renal involvement, and arthritis. HSP primarily affects children and less common in adults and it is usually self limited [1], [2]. Here we report a rare case of Henoch Scholein purpura in a postmenopausal woman presenting as acute distal ileitis.

\section{Case Report}

A 54 years old woman presented to our emergency room with complaints of right lower abdominal pain and vomiting for 7 days and hematochezia for past two days. She had high grade fever and arthralgia for two days before admission. She is hypertensive since two years for which she was on amlodipine $5 \mathrm{mg}$ once a day. On physical examination, the vital signs were as follows: temperature-37.5 degree celsius; heart rate-94/min; respiratory rate- 20/min; blood pressure-120/74mm $\mathrm{Hg}$. Multiple non blanchable non itchy palpable purpuric lesions were noted in both the lower limbs as shown in Figure 1. The abdominal examination was significant for tenderness and pain in the right lower quadrant upon palpation. There was no rebound tenderness or muscle rigidity. Bowel sounds were present. The remainder of the physical examination was normal.

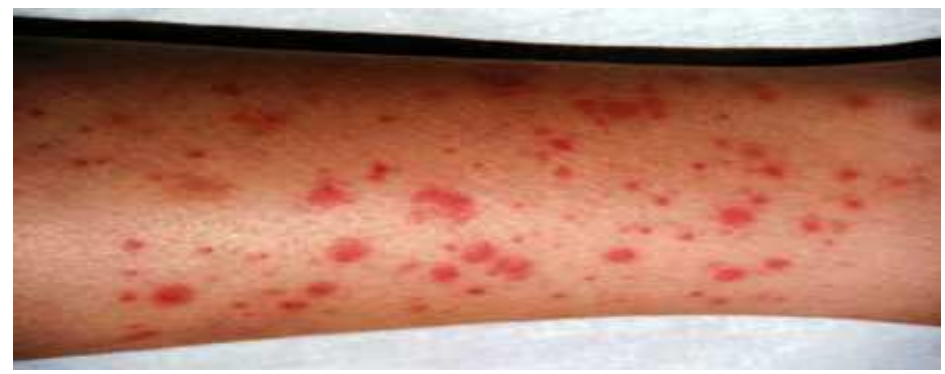

Figure-1: Multiple palpable purpura in left lower limb at admission.

Manuscript received $15^{\text {th }}$ June 2016

Reviewed: $27^{\text {th }}$ June 2016

Author Corrected: $13^{\text {th }}$ July 2016

Accepted for Publication $23^{\text {rd }}$ July 2016 


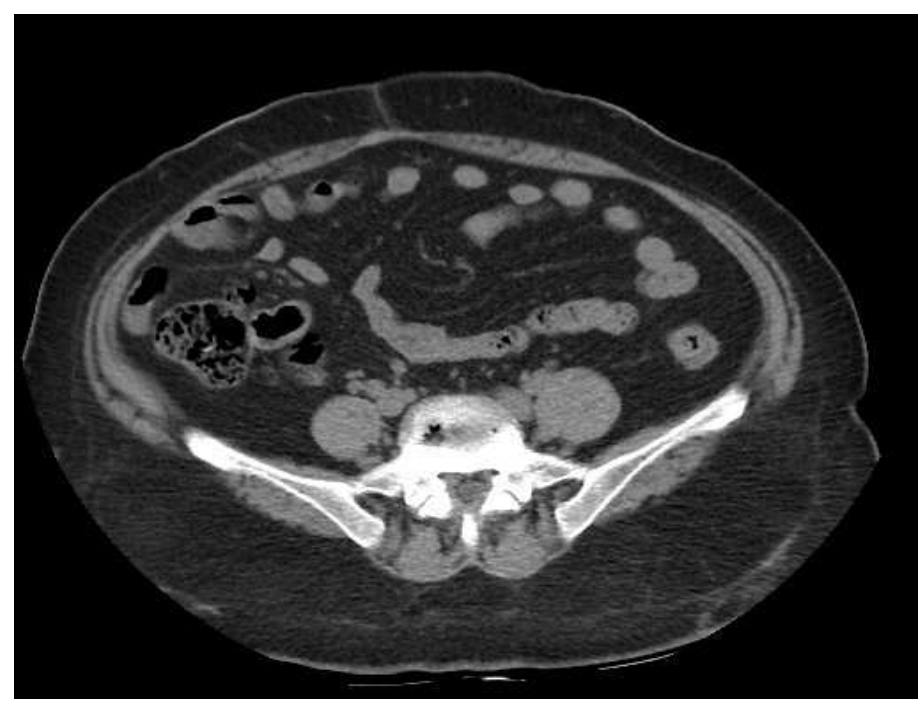

Figure-2: CT Abdomen showing circumferential thickening of distal ileum

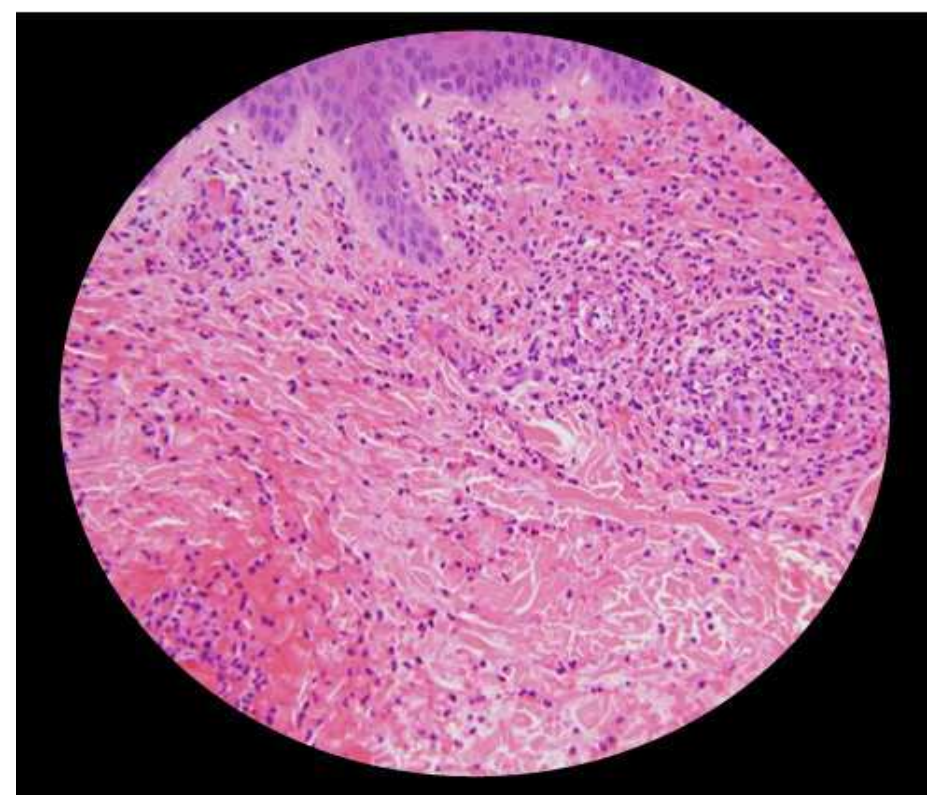

Figure-3: Skin biopsy suggestive of leukocytoclastic vasculitis with neutrophil infiltration and fibrinoid necrosis within the vessel wall

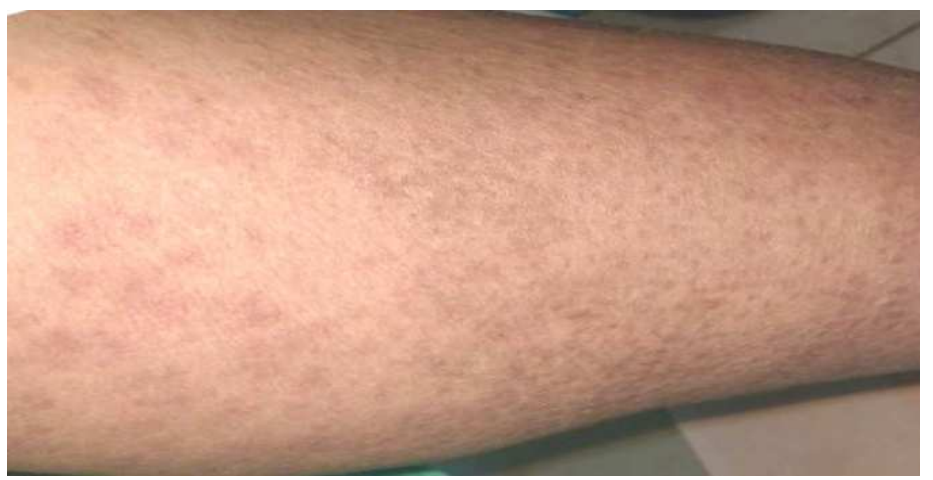

Figure-4: Skin showing resolution of purpura and post inflammatory hyperpigmentation after 10 days 
Laboratory testing revealed the following: white blood cell Count-22800cells/cu.mm with $70 \%$ Neutrophils and $26 \%$ lymphocytes. Hemoglobin was $12.7 \mathrm{~g} / \mathrm{L}$ and platelet count was 4.08 lakhs/cumm. ESR was 56mm/hr. Urea-40mg/dl and creatinine-1.7mg/dl. Urine analysis showed 15-16rbcs/HPF but no albuminuria. Stool culture showed no growth. CT abdomen showed circumferential thickening in distal ileum and fatty liver (Figure 2). All other reports were normal. Initially patient was given antibiotics, IV fluids, Analgesics, supportive therapy but later antibiotics were stopped on reviewing with CT abdomen report and skin biopsy report showing leukocytoclastic vasculitis (Figure 3). Patient improved after supportive therapy without need of steroids and she was further monitored with urine analysis for resolution of hematuria (Figure 4). At discharge, the serum creatinine was $1.4 \mathrm{mg} / \mathrm{dl}$.

\section{Discussion}

Henoch-Schönlein purpura (HSP) is an acute nonthrombocytopenic immunoglobulin A ( $\operatorname{Ig} \mathrm{A})$-mediated disorder characterized by a generalized vasculitis involving the small vessels of the skin, the gastrointestinal tract, the kidneys, the joints, and rarely the lungs and the central nervous system. HenochSchönlein purpura is common in children and it occurs twice as often in males as in females [3]. It occurs most frequently in the spring and fall [4]. Worldwide, AfroCaribbeans have the least incidence while Asians have the highest incidence. As this disease is self limited, its true incidence may be under-reported.

The etiology of HSP is unclear but associated with infections (group A streptococci, Mycoplasma, EpsteinBarr Virus, Varicella virus, Campylobacter enteritis, etc.,) medications, vaccinations, tumors (non-small cell lung cancer, prostate cancer, and hematological malignancies) and alpha-1-antitrypsin deficiency [5].

The main pathophysiology of HSP is due to deposition of the antigen antibody complexes in the small vessel walls and activation of the alternate complement pathway which leads to neutrophil accumulation resulting in inflammation and vasculitis causing extravasation of blood and its components into the interstitial spaces resulting in edema and hemorrhage.

HSP usually presents with a classic tetrad of rash, polyarthralgias, abdominal pain and renal disease. The clinical presentation of HSP is more severe among adult and tends to be atypical. Abdominal pain is the most common symptom of the gastrointestinal tract in patients with HSP. The various gastrointestinal manifestations in patients with HSP are intussusception, ischemic necrosis of the bowel wall, intestinal perforation, massive gastrointestinal bleeding, acute acalculous cholecystitis, hemorrhagic ascites with serositis, pancreatitis, and biliary cirrhosis [6].

Cutaneous manifestations include non-thrombocytopenic rash which evolves from erythematous to urticarial and macular wheels to nonblanching palpable purpura with petechiae and ecchymoses. Palpable purpura is seen in $50 \%$ of the cases as the presenting sign and it is symmetrical in distribution involving dependent areas such as the lower extremities and buttocks but it can also be seen in the upper extremities, face and trunk. On histopathology, leukocytoclastic vasculitis characterized by neutrophilic infiltration and prominent nuclear fragmentation, involving the upper and middle layers of the dermis with IgA deposition on immunofluorescence is seen.

Cutaneous symptoms often precede gastrointestinal symptoms in patients with HSP; nevertheless, skin lesions occur after gastrointestinal manifestations in $25 \%$ of patients, which make the diagnosis difficult [7]. The Joint involvement is usually non-migratory, nondestructive, symmetrical polyarthralgia mostly involving the knees and ankles.

Hematuria (microscopic or gross) is the most common renal manifestation. Most of the cases of HSP nephritis resolve spontaneously, only 5\% progress to chronic end-stage renal disease (ESRD) at 5 years. Renal involvement is similar to $\operatorname{IgA}$ nephropathy and patients should be followed for a year with urinalysis. Other rare manifestations may include hepatosplenomegaly, myocardial infarction, pulmonary hemorrhage, pleural effusion, behavioral changes, seizures, headaches, focal neurological deficit, mononeuropathies. HSP is a clinical diagnosis but when the presentation is atypical, tissue biopsy may be helpful [8], [9]. There are two criteria for diagnosing HSP which are formulated by ACR and European League against Rheumatism (EuLAR) [8], [9].

There is no specific treatment for Henoch-Schönlein purpura. Bed rest and supportive care, such as assuring adequate hydration, are helpful. Nonsteroidal antiinflammatory drugs can relieve joint and soft tissue discomfort. Corticosteroids have some use in patients with severe abdominal pain. However, corticosteroids 
are not recommended for treatment of rash, joint pain or renal disease alone.

Treatment with Immunosuppressants is controversial. In the absence of renal disease and central nervous system involvement, the prognosis for patients with HenochSchönlein purpura is excellent.

\section{Conclusion}

This case was presented as Henoch scholein purpura is rare in adults and its presentation as distal ileitis mimicking infective or inflammatory disease is further rare posing a diagnostic challenge. Physicians should recognise the wide spectrum of presentation of Henoch scholein purpura to avoid overzealous investigations and surgical procedures as most of the times its self limiting disease [10].

Funding: Nil, Conflict of interest: None initiated, Permission from IRB: Yes

\section{References}

1. Roberts PF, Waller TA, Brinker TM, Riffe IZ, Sayre JW, Bratton RL. Henoch-Schönlein purpura: a review article. South Med J. 2007 Aug;100(8):821-4.

2. Sohagia AB, Gunturu SG, Tong TR, Hertan HI. Henoch-schonlein purpura-a case report and review of the literature. Gastroenterol Res Pract. 2010;2010: 597648. doi: 10.1155/2010/597648. Epub 2010 May 23.

3. Jennette JC, Falk RJ. Small-vessel vasculitis. N Engl J Med. 1997 Nov 20;337(21):1512-23.
4. Trujillo H, Gunasekaran TS, Eisenberg GM, Pojman D, Kallen R. Henoch-Schönlein purpura: a diagnosis not to be forgotten. J Fam Pract. 1996 Nov;43(5):495-8.

5. Chen KR, Carlson JA. Clinical approach to cutaneous vasculitis. Am J Clin Dermatol. 2008;9(2):71-92.

6.Kim CJ, Chung HY, Kim SY, Kim YO, Ryu SY, Kim JC, Chung JH. Acute appendicitis in Henoch-Schönlein purpura: a case report. J Korean Med Sci. 2005 Oct; 20(5):899-900.

7. Trouillier S, Andre M, Delevaux I, et al. Abdominal manifestations of Henoch-Schönlein purpura in adults: a retrospective study of 23 cases. La Revue de Médecine Interne.2009;30(8):661-670.

8. Mills JA, Michel BA, Bloch DA, Calabrese LH, Hunder GG, Arend WP, Edworthy SM, Fauci AS, Leavitt RY, Lie JT, et al. The American College of Rheumatology 1990 criteria for the classification of Henoch-Schönlein purpura. Arthritis Rheum. 1990 Aug;33(8):1114-21.

9. Ozen S, Ruperto N, Dillon MJ, Bagga A, Barron K, Davin JC, Kawasaki T, Lindsley C, Petty RE, Prieur AM, Ravelli A, Woo P. EULAR/PReS endorsed consensus criteria for the classification of childhood vasculitides. Ann Rheum Dis. 2006 Jul;65(7):936-41. Epub 2005 Dec 1.

10. Yentis I. Henoch-Schönlein purpura mimicking acute appendicitis and Crohn's disease. Br J Radiol. 1973 Jul;46(547):555-6.

\section{How to cite this article?}

Ramya SG, SK Nelliappa Ganesan, SN Meenakshi Sundari, V Sundaravadivelu, P Priyadharshini. Henoch scholein purpura presenting as distal ileitis in a postmenopausal woman: A rare case report. Int J Med Res Rev 2016;4 (7):12071210.doi:10.17511/ijmrr.2016.i07.22. 